\title{
Older soft tissue sarcoma patients experience increased rates of venous thromboembolic events: a retrospective cohort study of SEER-Medicare data
}

\author{
Sumitra Shantakumar ${ }^{\text {** }}$, Alexandra Connelly-Frost ${ }^{2}$, Monica G Kobayashi ${ }^{3}$, Robert Allis ${ }^{3}$ and Li Li ${ }^{4}$
}

\begin{abstract}
Background: Venous thromboembolic co-morbidities can have a significant impact on treatment response, treatment options, quality of life, and ultimately, survival from cancer. There is a dearth of published information on venous thromboembolic co-morbidity among older soft tissue sarcoma patients.

Methods: SEER-Medicare linked data (1993-2005) was utilized for this retrospective cohort analysis ( $n=3,480$ soft tissue sarcoma patients). Non-cancer patients were frequency-matched by age to cancer patients at a ratio of 1:1; coverage and follow-up requirements were the same as for soft tissue sarcoma cases. Venous thromboembolic events were divided into three groups of interest: deep vein thrombosis, pulmonary embolism, and other thromboembolic events. Relative incidence rates of venous thromboembolic events in soft tissue sarcoma patients with a recent history of cardiovascular event or venous thromboembolic event (12 months before diagnosis) versus soft tissue sarcoma patients without such a recent history were calculated using the Cox proportional hazard models. The Cox proportional hazard model was used to build predictive models to identify important risk factors for each venous thromboembolic event of interest among soft tissue sarcoma patients. Relative incidence rate of VTEs in cancer patients (12 months after diagnosis) versus non-cancer cases (12 months after index date) was calculated using multivariable Cox proportional hazard models.

Results: We observed that among older soft tissue sarcoma patients, $10.6 \%$ experienced a deep vein thrombosis, 3.0\% experienced a pulmonary embolism, and 3.1\% experienced other thromboembolic events in the 12 months after sarcoma diagnosis. On average, $60 \%$ of venous thromboembolic events occurred in the first 90 days after sarcoma diagnosis. The highest rates of deep vein thrombosis and pulmonary embolism after sarcoma diagnosis were seen in patients with sarcoma not otherwise specified (deep vein thrombosis: 204/1,000 p-y and pulmonary embolism: 50/1,000 p-y). Recent history of a venous thromboembolic event was the strongest predictor of a subsequent venous thromboembolic event after soft tissue sarcoma diagnosis.
\end{abstract}

Conclusion: Venous thromboembolic events are common and serious co-morbidities that should be closely monitored in older soft tissue sarcoma patients.

Keywords: Soft tissue sarcoma, Venous thromboembolic events, Deep vein thrombosis, Pulmonary embolism, Co-morbidity, Elderly

\footnotetext{
*Correspondence: sumitra.y.shantakumar@gsk.com

1 Worldwide Epidemiology, Research and Development, GlaxoSmithKline,

150 Beach Road, \#26-00 Gateway West, Singapore 189720, Singapore

Full list of author information is available at the end of the article
} 


\section{Background}

Venous thromboembolic co-morbidities among cancer patients can have a significant impact on quality of life, treatment options, treatment response, and ultimately, survival from cancer [1-3]. A small body of evidence is developing for brain, breast, lung, ovarian, and pancreatic cancers, suggesting that the incidence of venous thromboembolic events (VTEs) VTEs varies substantially by cancer subtype [2, 4-13]. Estimates for the occurrence of VTEs in these cancers range from as low as $0.4 \%$ up to $26.0 \%$, depending on the cancer type, study population, and the length of follow-up [12]. Because the risk of VTEs differs by the histological type of each cancer, it is important to carefully characterize this co-morbidity by cancer subtype.

There is a dearth of information on the extent of venous thromboembolic co-morbidity among older soft tissue sarcoma (STS) patients in the literature. VTE incidence among STS patients has rarely been addressed, timing of VTEs has not been investigated, co-factors have not been considered, soft tissue and bone sarcomas are usually combined, and older populations have not been studied. It is important to understand the scope of VTEs, before and after diagnosis, in order to offer STS patients optimal care and improved quality of life.

The main goals of this study were (1) to estimate the incidence of VTEs before STS diagnosis and during 90-day time periods after STS diagnosis and (2) to produce adjusted relative risk estimates of VTEs for STS patients with and without a cardiovascular disease or VTE history and (3) to compare risk of VTEs for STS patients versus age-matched non-cancer individuals.

\section{Methods}

\section{Study population}

SEER-Medicare data is a linkage of US cancer registry data with Medicare claims data. This database combines two large, population-based, geographically diverse US data sources, providing detailed information about older persons ( $\geq 65$ years) with and without cancer. Data from 1993 to 2005 were utilized for this retrospective cohort analysis. Patients 65 years of age and over who were diagnosed with STS and had at least 24 months of continuous non-HMO Medicare coverage (Parts A and $B$ ) before diagnosis and 1-12 months of follow-up information after diagnosis were included in the cancer cohort. Duration of patient follow-up after diagnosis (maximum 12 months) was the number of months until the patient died or lost Medicare coverage. If neither of these events occurred before the end of the planned follow-up time after diagnosis, the patient was followed for the full 12 months. Non-cancer patients were frequency-matched by age to cancer patients at a ratio of
1:1; and coverage and follow-up requirements were the same as for STS cases. VTEs of interest were deep vein thrombosis (DVT), pulmonary embolism (PE), and other thromboembolic events (OTE). Thromboembolic events included in the OTE category were as follows: central retinal vein occlusion, venous tributary (branch) occlusion, nonpyogenic thrombosis of intracranial venous sinus, phlebitis/thrombophlebitis of superficial veins of lower and upper extremities, phlebitis/thrombophlebitis of other sites, gout with other specified manifestations, Budd-Chiari syndrome, venous embolism/thrombosis of renal vein, and portal vein thrombosis. ICD-9 diagnosis codes were used to identify VTEs and ICD-O-3 codes were used to identify STS patients (overall and by subtype). Types and definitions of STS by ICD-O-3 histology codes are as follows: GIST $(8935,8936)$, leiomyosarcoma (8890-91, 8894-97), malignant fibrous histiocytoma (8830), liposarcoma $(8850-8855,8858)$, dermatofibrosarcoma (8832, 8833), rhabdomyosarcoma (8900-8902, 8910, 8912, 8920), angiosarcoma (9120, 9130, 9133, 9170), nerve sheath tumor (9540, 9560-62), fibrosarcoma $(8810,8811,8814,8815$ ), sarcoma NOS (not otherwise specified) (8800-8805), Ewing Sarcoma/primitive neuroectodermal tumor (9260, 9364, 9365, 9473), extraskeletal osteosarcoma (9180, 9181), extraskeletal chondrosarcoma (9220, 9231, 9240), synovial sarcoma (9040-9043), clear cell sarcoma (9044), myxosarcoma (8840), malignant hemangiopericytoma (9150), malignant giant cell tumor $(9251,9252)$, malignant granular cell tumor (9580), alveolar soft part sarcoma (9581), and desmoplastic small round cell tumor (8806). Bone and joint sites were excluded for all above mentioned diagnoses as were non-malignant tumor types. DVT was captured using ICD-9 codes of 451.1 (451.11, 451.19) 451.2, 451.81, 451.83, 451.84, 453.1, 453.2, 453.4 (453.40, 453.41, 453.42) 453.8, and 453.9; PE was captured using ICD-9 codes of 415.1 and 415.19; and OTEs were captured using ICD-9 codes of $362.35,362.36,437.6,451.0$, 451.82, 451.89, 451.9, 453.0, 453.3, and 452 .

\section{Statistical analysis STS patients}

Incidence rates of each VTE (a) in the 12 months before diagnosis and (b) in the 12 months after diagnosis were described by age, race, sex, stage at diagnosis, and year of diagnosis. The numerator is the number of events that occurred over the respective 12-month period and the denominator was the person-years at risk. Events in the 12 months after diagnosis were further described as the proportion of cases with a first event in discrete time intervals of follow-up time (0-90 days, $91-180$ days, 181-270 days, and 271-365 days). The numerator of each incidence proportion is the number of persons with their 
first event of interest during that time period only, while the denominator represents the persons who were alive and free of events at the beginning of the period.

Relative incidence rates of VTEs in STS patients with a recent history of cardiovascular event (CV) or VTE event (12 months before diagnosis) versus STS patients without such a recent history were calculated using the Cox proportional hazard models. Using a commonly used definition present in the literature, history of CV event was defined as any of the following events in the 12 months before STS diagnosis: myocardial infarction, ischemic stroke, congestive heart failure, angina, or TIA in the prior 12 months. The first VTE outcome was counted for each patient from time of diagnosis up to 12 months after diagnosis. Potential confounders, identified through ICD-9 diagnosis and procedure codes, were as follows: age at diagnosis, race, sex, diabetes, hypercholesterolemia, atherosclerosis, varicose veins, recent highrisk surgical procedure, central venous catheter, kidney disease, stage at diagnosis, surgery of primary tumor, chemotherapy, history of cancer. Results are presented by major STS subtypes [angiosarcoma, fibrosarcoma, GIST, leiomyosarcoma, liposarcoma, malignant fibrous histiosarcoma (MFH), nerve sheath tumor, and sarcoma NOS] where cell sizes permit.

The Cox proportional hazard model was used to build predictive models to identify important risk factors for each VTE of interest among STS patients. Potential risk factors included in the initial (full) model were as follows: age at diagnosis, race, sex, diabetes, hypercholesterolemia, atherosclerosis, varicose veins, recent high-risk surgical procedure, central venous catheter, kidney disease, stage at diagnosis, chemotherapy, hormone therapy, surgery of primary tumor, history of cancer, and recent history of VTE of interest. After stepwise backwards elimination, risk factors with a multivariable $p$ value $<0.1$ were retained in the final multivariable predictive model.

\section{STS vs. non-cancer patients}

A matched-cohort design was utilized to evaluate the relative incidence rate of VTEs in STS patients (12 months before diagnosis) versus non-cancer cases (12 months before index date). Multivariable logistic regression modeling was performed. Potential confounders assessed were as follows: race, sex, diabetes, hypercholesterolemia, atherosclerosis, varicose veins, recent high-risk surgical procedure, central venous catheter, kidney disease, recent history of cardiovascular or VTEs. All models were adjusted for age to account for the age-matched design.

Relative incidence rate of VTEs in cancer patients (12 months after diagnosis) versus non-cancer cases (12 months after index date) was calculated using multivariable Cox proportional hazard models. Matching was accounted for by including the matching variable (age) in the STRATA statement. Potential confounders assessed were the same as in aforementioned logistic regression models. Where possible, results are presented by major STS subtypes [angiosarcoma, fibrosarcoma, GIST, leiomyosarcoma, liposarcoma, malignant fibrous histiosarcoma (MFH), nerve sheath tumor, sarcoma NOS]. Sas 9.1 was used to perform all analyses.

\section{Results}

The study population for the first series of analyses consisted of 3,480 STS patients 65 years of age and older (median age $=77$ ). Eighty-five percent of the population was white, $9 \%$ of the population was black, and $6 \%$ was another race. Forty-seven percent of STS patients were male. The distribution of cases by stage was as follows: $43 \%$ localized, $23 \%$ regional, $21 \%$ distant, and $14 \%$ unstaged. The most common STS subtypes in our data were sarcoma NOS (40.9\%), GIST (24.3\%), leiomyosarcoma (7.6\%), MFH (6.4\%), and angiosarcoma (5.3\%) (Table 1). The two most common primary sites were connective or subcutaneous tissue (35.0\%) and the digestive system (31.8\%) (Table 1). The non-cancer comparison cohort $(\mathrm{n}=3,480)$ was similar in its distribution of age, race, and sex (Table 1).

\section{STS patients}

Among STS patients, DVTs occurred at the highest rate (149/1,000 person-years) of all VTEs after diagnosis (Table 2). The unadjusted incidence rate of VTEs was 1.7-4.1 times higher during the 12-month period after STS diagnosis than the 12-month period prior to cancer diagnosis (Table 2). Regardless of VTE type, over half of VTEs occurred in the first 90 days after STS diagnosis: DVT: $62 \%$ (228/367), PE: 67\% (70/105), and OTE: 51\% $(55 / 108)$. This pattern did not vary by STS subtype (data not shown).

When STS cases were stratified further by subtype, the highest rates of DVT and PE were seen in sarcoma NOS patients (DVT: 204/1,000 p-y and PE: 50/1,000 p-y). Rates of OTEs ranged from $18 / 1,000$ to $50 / 1,000$; however, estimates for most subtypes were based on very small numbers (Table 3). Unadjusted analyses revealed that STS patients with a recent history of a VTE had substantially higher rates of that specific VTE after STS diagnosis than those without history of that VTE (Table 3). STS patients with a recent history of a CVD event had slightly higher rates of VTEs after STS diagnosis than those without history of a CVD event. Patients of advanced or regional STS stage had higher rates of VTEs after diagnosis compared to patients with localized disease. Patients who were treated with chemotherapy were also more likely compared to patients without chemotherapy to 
Table 1 SEER-Medicare study population (1993-2005): soft tissue sarcoma patients $(n=3,480)$ and non-cancer controls $(n=3,480)$

\begin{tabular}{|c|c|c|c|c|}
\hline & \multicolumn{2}{|c|}{ Cancer } & \multicolumn{2}{|c|}{ Non-cancer } \\
\hline & $\mathbf{n}$ & $\%$ & $\mathrm{~N}$ & $\%$ \\
\hline \multicolumn{5}{|l|}{ Age in years } \\
\hline $65-69$ & 475 & 13.7 & 549 & 15.8 \\
\hline $70-74$ & 825 & 23.7 & 836 & 24.0 \\
\hline $75-79$ & 880 & 25.3 & 853 & 24.5 \\
\hline $80-84$ & 744 & 21.4 & 715 & 20.6 \\
\hline $85+$ & 556 & 16.0 & 527 & 15.1 \\
\hline \multicolumn{5}{|l|}{ Race } \\
\hline Black & 300 & 8.6 & 301 & 8.7 \\
\hline White & 2,967 & 85.3 & 2,945 & 84.6 \\
\hline Other/unknown race & 213 & 6.1 & 234 & 6.7 \\
\hline \multicolumn{5}{|l|}{ Sex } \\
\hline Female & 1,843 & 53.0 & 1,972 & 56.7 \\
\hline Male & 1,637 & 47.0 & 1,508 & 43.3 \\
\hline \multicolumn{5}{|l|}{ STS subtype } \\
\hline Sarcoma NOS & 1,422 & 40.9 & na & na \\
\hline GIST & 845 & 24.3 & na & na \\
\hline Leiomyosarcoma & 264 & 7.6 & na & na \\
\hline Maligant fibrous histiocytoma & 224 & 6.4 & na & na \\
\hline Angiosarcoma & 184 & 5.3 & na & na \\
\hline Liposaroma & 136 & 3.9 & na & na \\
\hline Nerve sheath tumor & 118 & 3.4 & na & na \\
\hline Fibrosarcoma & 64 & 1.8 & na & na \\
\hline Synovial Sarcoma & 49 & 1.4 & na & na \\
\hline Osteosarcoma & 44 & 1.3 & na & na \\
\hline Rhabdomyosarcoma & 25 & 0.7 & na & na \\
\hline Chondrosarcoma & 25 & 0.7 & na & na \\
\hline Dermatofibrosaroma & 22 & 0.6 & na & na \\
\hline Ewing sarcoma & 19 & 0.5 & na & na \\
\hline Maligant hemangiopericytoma & 15 & 0.4 & na & na \\
\hline Clear cell sarcoma & $<11$ & 0.3 & na & na \\
\hline Myxosarcoma & $<11$ & 0.2 & na & na \\
\hline Alveolar soft part & $<11$ & 0.1 & na & na \\
\hline Maligant granular cell tumor & $<11$ & 0.1 & na & na \\
\hline Maligant giant cell tumor & $<11$ & 0.0 & na & na \\
\hline \multicolumn{5}{|l|}{ Primary site } \\
\hline Connective/subcutaneous tissue & 1,217 & 35.0 & na & na \\
\hline Digestive system & 1,107 & 31.8 & na & na \\
\hline Respiratory system & 279 & 8.0 & na & na \\
\hline Breast & 178 & 7.7 & na & na \\
\hline Other non-epithelial skin & 167 & 5.1 & na & na \\
\hline Female genital system & 160 & 4.8 & na & na \\
\hline Urinary system & 105 & 4.6 & na & na \\
\hline Other and unknown & 267 & 3.0 & na & na \\
\hline \multicolumn{5}{|l|}{ Stage } \\
\hline Unstaged & 482 & 13.9 & na & na \\
\hline Localized & 1,482 & 42.6 & na & na \\
\hline
\end{tabular}

Table 1 continued

\begin{tabular}{|c|c|c|c|c|}
\hline & \multicolumn{2}{|c|}{ Cancer } & \multicolumn{2}{|c|}{ Non-cancer } \\
\hline & $n$ & $\%$ & $\mathrm{~N}$ & $\%$ \\
\hline Regional & 800 & 23.0 & na & na \\
\hline Distant & 716 & 20.5 & na & na \\
\hline
\end{tabular}

experience a VTE after STS diagnosis. Patients who were treated with surgery of their primary tumor were half as likely as patients without surgery to experience a VTE after STS diagnosis.

Multivariable modeling was conducted to more closely evaluate the association between VTE history and incidence of VTEs after sarcoma diagnosis by STS subtype. Overall, history of a VTE in the 12 months before sarcoma diagnosis substantially increased the risk of a subsequent VTE in the 12 months after STS diagnosis (HR range $=6.4-49.3$ ) (Table 4). Although all age-adjusted associations were strong, the most marked associations were seen in patients with leiomyosarcoma $(\mathrm{HR}=49.3,95 \% \mathrm{CI}=22.2-109.0)$, GIST $(\mathrm{HR}=20.9,95 \% \mathrm{CI}=13.6-32.2)$, and liposarcoma $(\mathrm{HR}=19.1,95 \% \mathrm{CI}=4.2-87.4)($ Table 4$)$.

Predictors of each VTE subtype after sarcoma diagnosis were evaluated among the combined group of STS patients. There were only two statistically significant predictors of increased risk of PE after STS diagnosis: atherosclerosis and recent history of PE. There were four predictors of increased risk of OTE after STS diagnosis: atherosclerosis, hormone therapy, recent history of OTE and varicose veins. There were multiple predictors of both increased risk and decreased risk of DVT among the combined group of STS patients. Predictors of increased risk of DVT included kidney disease, radiation treatment, regional or distant stage and varicose veins; predictors of decreased risk of DVT included surgery of primary, high risk surgery, and central venous catheter. By far, the strongest predictor of all VTE events after STS diagnosis was a history of that same event in the 12 months before diagnosis (DVT: $\mathrm{HR}=7.6,95 \% \mathrm{CI}=5.7-10.1$; PE: $\mathrm{HR}=17.6,95 \% \mathrm{CI}=9.4-33.0$; OTE: $\mathrm{HR}=16.6,95 \%$ $\mathrm{CI}=10.8-25.4$ ) (data not shown). Presence of atherosclerosis was also an important predictor for all VTE events, associated with a 1.8-2.5 times greater risk of VTE (DVT: $\mathrm{HR}=1.8,95 \% \mathrm{CI}=1.4-2.3$; PE: $\mathrm{HR}=2.0,95 \% \mathrm{CI}=1.3$ 3.1; OTE: $\mathrm{HR}=2.5,95 \% \mathrm{CI}=1.7-3.8$ ) (data not shown).

\section{STS patients compared to an age-matched, non-cancer population}

Angiosarcoma and sarcoma NOS patients were more likely to have experienced a VTE in the recent past 
Table 2 Unadjusted incidence rates of venous thromboembolic events, before and after STS diagnosis

\begin{tabular}{|c|c|c|}
\hline $\begin{array}{l}\mathrm{n}=3,480 \mathrm{STS}^{\mathrm{a}} \\
\text { patients }\end{array}$ & $\begin{array}{l}\text { Incidence } 12 \text { months } \\
\text { before STS diagnosis }\end{array}$ & $\begin{array}{l}\text { Incidence } 12 \text { months } \\
\text { after STS diagnosis }\end{array}$ \\
\hline \multicolumn{3}{|l|}{$\mathrm{DV} \mathrm{T}^{\mathrm{a}}$} \\
\hline $\mathrm{n} /$ person-years $^{b}$ & $137 / 3,418$ & $367 / 2,468$ \\
\hline Rate/1,000 & $40.1(33.7-164.7)$ & $148.7(133.9-164.7)$ \\
\hline $\begin{array}{l}\text { Rate ratio (aftervs. } \\
\text { before) }\end{array}$ & - & $3.7(3.0-4.5)$ \\
\hline \multicolumn{3}{|l|}{$P E^{a}$} \\
\hline $\mathrm{n} /$ person-years $^{\mathrm{b}}$ & $34 / 3,463$ & $105 / 2,589$ \\
\hline Rate/1,000 & $9.8(6.8-49.1)$ & $40.6(33.2-49.1)$ \\
\hline $\begin{array}{l}\text { Rate ratio (aftervs. } \\
\text { before) }\end{array}$ & - & $4.1(2.8-6.1)$ \\
\hline \multicolumn{3}{|l|}{ OTE ${ }^{a}$} \\
\hline $\mathrm{n} /$ person-years $^{\mathrm{b}}$ & $82 / 3,438$ & $106 / 2,590$ \\
\hline Rate $/ 1,000^{c}$ & $23.9(19.0-49.5)$ & $40.9(33.5-49.5)$ \\
\hline $\begin{array}{l}\text { Rate ratio (aftervs. } \\
\text { before) }\end{array}$ & - & $1.7(1.3-2.3)$ \\
\hline
\end{tabular}

Rate ratios are highlighted in italics.

a VTE venous thromboembolic events, STS soft tissue sarcoma, DVT deep vein thrombosis, PE pulmonary embolism, OTE other thromboembolic event. OTE category includes the following diagnoses: central retinal vein occlusion, venous tributary (branch) occlusion, nonpyogenic thrombosis of intracranial venous sinus, phlebitis/thrombophlebitis of superficial vessels of lower extremities, phlebitis/thrombophlebitis of superficial veins of upper extremities, phlebitis/ thrombophlebitis of other sites, gout with other specified manifestations, BuddChiari syndrome, and venous embolism/thrombosis of renal vein.

b $n$ number of VTE events, $p$-y person-years.

c Rates are per 1,000 person-years and are unadjusted. Age adjustment is unnecessary as these rates are intentionally representative of the older subpopulation (ages 65+) of STS patients. Only first VTE counted in rate estimates.

d Rate ratios are unadjusted.

(i.e. 12 month prior to STS diagnosis/index date) than non-cancer individuals (Table 5). A strong association between STS and VTE after diagnosis (or index date for non-cancer patients) was observed in most STS subtypes. The strongest comparisons of VTE after diagnosis for cancer versus non-cancer patients were among angiosarcoma $(\mathrm{HR}=9.1,95 \% \mathrm{CI}=2.1-39.5)$, leiomyosarcoma $(\mathrm{HR}=5.5,95 \% \mathrm{CI}=2.1-15.0)$ and sarcoma NOS patients $(\mathrm{HR}=5.2,95 \% \mathrm{CI}=3.8-6.9)$ (Table 5).

\section{Discussion}

We studied the incidence of venous thromboembolic events before and after soft tissue sarcoma diagnosis. There are only four published studies, to our knowledge, that have investigated VTEs in adult STS patients. Two of these are large studies of thromboembolic events among cancer patients that include sarcomas as a cancer site [6, 7]. Khorana et al. [6] reported results from a retrospective cohort study ( $\mathrm{n}=1,597$ sarcoma patients) including patients receiving chemotherapy at any one of 115
University HealthSystem Consortium locations between the years of 1995 and 2002. During their first hospitalization for neutropenia, $4.8 \%$ of sarcoma patients had a VTE. Khorana et al. [7] conducted a retrospective cohort study ( $n=21,989$ sarcoma cases) of the same health consortium and found that $2.9 \%$ of sarcoma patients experienced a VTE during one hospitalization following cancer diagnosis. Results from these two large studies are difficult to compare to our incidence proportions for several reasons: in these studies, bone sarcomas were included in their sarcoma category, median age of the sarcoma group was not stated, and incidence proportions were based on a VTE diagnosis during a single hospitalization. Our analysis evaluated incidence proportions and incidence rates (Table 2) over the full 12-month period (or death) after diagnosis.

Two studies reported incidence of venous thromboembolic events (VTEs) among soft tissue sarcoma patients, specifically $[14,15]$. Mitchell et al. [15] conducted a retrospective cohort study of VTE events among trunk/ extremity soft tissue or bone sarcoma patients presenting to their unit between 1998 and 2003. Among STS patients $(\mathrm{n}=158), 5.0 \%$ experienced a DVT and $1.3 \%$ experienced a PE after diagnosis. Damron et al. [14] conducted a retrospective cohort study of patients receiving surgery for bone and soft tissue sarcoma of the head, neck, upper extremity and lower extremity. There were 120 STS cases included and $4.2 \%$ of those cases experienced one or more VTE following surgery (2.5\% DVT and 2.5\% PE). Incidence proportions from these two studies were lower than what we found in our study (10.6\% DVT and 3.0\% $\mathrm{PE})$. Both of these studies, however, were very small and had much younger patient populations than ours.

Our study found that STS patients undergoing chemotherapy were roughly $50 \%$ more likely (DVT: RR $=1.7$, PE: $\mathrm{RR}=1.5$, OTE: $\mathrm{RR}=1.4$ ) to experience a DVT, PE or OTE after diagnosis, although only about $10 \%$ of our STS patients received chemotherapy treatment (Table 3). Damron et al. [14] reported a similar result; STS patients undergoing chemotherapy treatment were at an increased risk of VTE compared to those not receiving chemotherapy $(\mathrm{p}=0.04)$.

An important component of our analysis was the evaluation of VTE history as a risk factor for future VTE events. Our results suggest that VTE history is the most important factor to consider in evaluating risk of future VTE in STS patients. There are no other studies in the current literature that quantify the association between VTE history and future events among STS patients; however, this result is consistent with broader studies of VTE among cancer patients $[16,17]$.

The major risk factors for VTEs among cancer patients reported in the literature are increased age, female sex, African American race, renal disease, infection, 
Table 3 Unadjusted incidence rates of venous thromboembolic events after cancer diagnosis among older STS patients

\begin{tabular}{|c|c|c|c|c|c|c|}
\hline & \multicolumn{2}{|l|}{$\mathrm{DVT}^{\mathrm{a}}$} & \multicolumn{2}{|l|}{$\mathrm{PE}^{\mathrm{a}}$} & \multicolumn{2}{|l|}{ OTE $^{a}$} \\
\hline & $N / P-Y^{b}$ & Rate $/ 1,000^{C}(95 \% \mathrm{Cl})$ & $N / P-Y^{b}$ & Rate $/ 1,000^{c}(95 \% \mathrm{Cl})$ & $N / P-Y^{b}$ & Rate/1,000 $(95 \% \mathrm{Cl})$ \\
\hline \multicolumn{7}{|l|}{ By major STS subtype } \\
\hline Angiosarcoma $(n=184)$ & $14 / 147$ & $95.4(52.1,160.0)$ & $<11$ & $26.5(7.2,68.0)$ & $<11$ & $39.8(14.6,86.6)$ \\
\hline Fibrosarcoma $(n=64)$ & $<11$ & $72.1(19.6,184.5)$ & 0 & 0 & $<11$ & $17.6(0.4,97.8)$ \\
\hline GIST $(n=845)$ & $94 / 683$ & $137.6(111.2,168.4)$ & $33 / 721$ & $45.7(31.5,64.2)$ & $23 / 730$ & $31.5(20.0,47.3)$ \\
\hline Leiomyosarcoma $(n=264)$ & $19 / 210$ & $90.6(54.5,141.4)$ & $<11$ & $28.0(10.3,60.8)$ & $<11$ & $32.6(13.1,67.1)$ \\
\hline Liposarcoma $(n=224)$ & $13 / 118$ & $110.1(58.6,188.2)$ & $<11$ & $24.5(5.1,71.7)$ & $<11$ & $24.5(5.0,71.5)$ \\
\hline MFH $(n=184)$ & 20/178 & $112.2(68.5,173.3)$ & $<11$ & $21.9(6.0,55.9)$ & $<11$ & $27.3(8.9,63.6)$ \\
\hline Nerve sheath tumor $(n=118)$ & $15 / 93$ & $160.8(90.0,265.3)$ & $<11$ & $40.7(11.1,104.2)$ & $<11$ & $49.8(16.2,116.3)$ \\
\hline Sarcoma, NOS $(n=1,422)$ & $166 / 812$ & $204.4(174.5,237.9)$ & $41 / 862$ & $47.5(34.1,64.5)$ & $41 / 858$ & $47.8(34.3,64.8)$ \\
\hline \multicolumn{7}{|l|}{ By history of $V T E^{e}$} \\
\hline Yes & $61 / 51$ & $1199.2(917.3-1540.5)$ & $11 / 14$ & 785.5 (392.3-1406.0) & $30 / 50$ & $599.2(404.3-855.4)$ \\
\hline No & $306 / 2,417$ & $126.6(112.8-141.6)$ & $94 / 2,575$ & $27.6(24.3-31.1)$ & $76 / 2,540$ & $29.9(23.6-37.5)$ \\
\hline Rate ratio (yes vs. no) ${ }^{d}$ & - & $9.5(7.2-12.5)$ & - & $21.5(11.5-40.2)$ & - & $20.0(13.1-30.6)$ \\
\hline \multicolumn{7}{|l|}{ By history of CVD event ${ }^{f}$} \\
\hline Yes & $120 / 579$ & $207.3(171.9-247.9)$ & $29 / 623$ & $46.6(31.2-66.9)$ & $39 / 619$ & $63.1(44.8-86.2)$ \\
\hline No & $247 / 1,889$ & $130.8(115.0-148.1)$ & $76 / 1,966$ & $38.7(30.5-48.4)$ & $67 / 1,971$ & $34.0(26.3-43.2)$ \\
\hline Rate ratio (yes vs. no) & - & $1.6(1.3-2.0)$ & & $1.2(0.8-1.8)$ & & $1.9(1.3-2.8)$ \\
\hline \multicolumn{7}{|l|}{ By disease stage } \\
\hline Localized & $133 / 1,236$ & $107.6(90.1-127.5)$ & $38 / 1,290$ & $29.5(20.9-40.4)$ & $34 / 1,295$ & $26.3(18.2-36.7)$ \\
\hline Regional & $93 / 586$ & $158.7(128.1-194.4)$ & $26 / 614$ & $42.3(27.7-62.1)$ & $34 / 610$ & $55.7(38.6-77.9)$ \\
\hline Distant & $86 / 380$ & $238.9(191.1-295.0)$ & $25 / 385$ & $65.0(42.1-95.9)$ & $19 / 387$ & $49.1(29.6-76.7)$ \\
\hline Rate ratio (regional and distant. vs. local) ${ }^{d}$ & - & $1.5(1.1-1.9)$ & - & $1.4(0.9-2.4)$ & - & $2.1(1.3-3.4)$ \\
\hline \multicolumn{7}{|l|}{ By chemotherapy } \\
\hline Yes & $74 / 324$ & $227.9(178.9-286.1)$ & $20 / 348$ & $57.5(35.1-88.7)$ & $19 / 346$ & $54.9(33.0-85.7)$ \\
\hline No & $293 / 2,413$ & $136.7(121.5-153.3)$ & $85 / 2,241$ & $37.9(30.3-46.9)$ & $87 / 2,244$ & $38.8(31.1-47.8)$ \\
\hline Rate ratio (yes vs. no) ${ }^{d}$ & - & $1.7(1.3-2.2)$ & - & $1.5(0.9-2.5)$ & & $1.4(0.9-2.3)$ \\
\hline \multicolumn{7}{|l|}{ By surgery of primary tumor } \\
\hline Yes & $247 / 1,976$ & $125.0(109.9-141.6)$ & $72 / 2,065$ & $34.9(27.3-43.9)$ & $76 / 2,064$ & $36.8(29.0-46.1)$ \\
\hline No & $115 / 467$ & $246.4(203.5-295.8)$ & $32 / 498$ & $64.2(43.9-90.7)$ & $29 / 501$ & $57.9(38.8-83.1)$ \\
\hline Rate ratio (yes vs. no) ${ }^{d}$ & - & $0.5(0.4-0.6)$ & - & $0.5(0.4-0.8)$ & - & $0.6(0.4-1.0)$ \\
\hline \multicolumn{7}{|l|}{ By Primary site } \\
\hline Connective/subcutaneous & $136 / 830$ & $163.9(137.5-193.8)$ & $33 / 877$ & $37.6(25.9-52.8)$ & $37 / 875$ & $42.3(29.8-58.3)$ \\
\hline Digestive system & $120 / 832$ & $144.2(119.5-172.4)$ & $38 / 879$ & $43.2(30.6-59.4)$ & $29 / 885$ & $32.8(22.0-47.1)$ \\
\hline Other/unknown ${ }^{9}$ & $111 / 805$ & $137.8(113.3-165.9)$ & $34 / 833$ & $40.8(28.3-57.0)$ & $40 / 830$ & $48.2(34.4-65.7)$ \\
\hline
\end{tabular}

Per SEER-Medicare data use agreement, cell sizes $<11$ cannot be displayed, nor can estimates that could be used to derive the undisplayed numbers $<11$. Rate ratios are highlighted in italics.

a DVT deep vein thrombosis, PE pulmonary embolism, OTE other thromboembolic event. OTE category includes the following diagnoses: central retinal vein occlusion, venous tributary (branch) occlusion, nonpyogenic thrombosis of intracranial venous sinus, phlebitis/thrombophlebitis of superficial vessels of lower extremities, phlebitis/thrombophlebitis of superficial veins of upper extremities, phlebitis/thrombophlebitis of other sites, gout with other specified manifestations, Budd-Chiari syndrome, and venous embolism/thrombosis of renal vein.

b N number of VTE events, $P-Y$ person-years.

c Rates are per 1,000 person-years and are unadjusted. Age adjustment is unnecessary as these rates are intentionally representative of the older subpopulation $(\geq 65$ years) of STS patients. Only first VTE counted in rate estimates.

d Rate ratios are unadjusted.

e History of VTE of interest in the 12 months before STS diagnosis.

f History of CVD is defined as a history of any of the following events in the 12 months before STS diagnosis: myocardial infarction, ischemic stroke, onset congestive heart failure, angina, or TIA.

g Other/unknown category includes primary sites of the breast, female genital system, other non-epithelial, respiratory system, urinary system, other sites and unknown sites. 
Table 4 Relative risk of VTE after STS diagnosis, recent versus no recent VTE history

\begin{tabular}{|c|c|c|}
\hline STS subtype ${ }^{a}$ & Hazard ratio & 95\% confidence interval \\
\hline Angiosarcoma & 6.4 & $(1.9-21.8)^{+}$ \\
\hline GIST & 20.9 & $(13.6-32.2)^{+}$ \\
\hline Leiomyosarcoma & 49.3 & $(22.2-109.0)^{+}$ \\
\hline Liposarcoma & 19.1 & $(4.2-87.4)^{+}$ \\
\hline $\mathrm{MFH}^{\mathrm{b}}$ & 11.9 & $(3.6-39.4)^{+}$ \\
\hline$N S T^{c}$ & 15.8 & $(5.8-42.7)^{+}$ \\
\hline Sarcoma NOS ${ }^{d}$ & 15.4 & $(10.9-21.8)^{+}$ \\
\hline
\end{tabular}

All models adjusted for age. Recent VTE history $=$ history of VTE in the 12 months before STS diagnosis. VTE venous thromboembolic event, including deep vein thrombosis, pulmonary embolism, and other thromboembolic events. The other thromboembolic event category includes the following diagnoses: central retinal vein occlusion, venous tributary (branch) occlusion, nonpyogenic thrombosis of intracranial venous sinus, phlebitis/thrombophlebitis of superficial vessels of lower extremities, phlebitis/thrombophlebitis of superficial veins of upper extremities, phlebitis/thrombophlebitis of other sites, gout with other specified manifestations, Budd-Chiari syndrome, and venous embolism/ thrombosis of renal vein.

a Hazard ratios for STS subtypes other than those listed were not estimable due to small numbers.

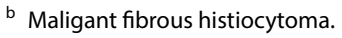

c Nerve sheath tumor.

d Sarcoma not otherwise specified.

+ Statistically significant.

Table 5 Relative risk of VTEs before and after STS diagnosis/index date: STS versus non-cancer cohort

\begin{tabular}{|c|c|c|}
\hline STS subtype ${ }^{a}$ & $\begin{array}{l}\text { Before odds ratio } \\
(95 \% \mathrm{Cl})\end{array}$ & $\begin{array}{l}\text { After hazard ratio } \\
(95 \% \mathrm{Cl})\end{array}$ \\
\hline Angiosarcoma & $4.0(1.4,11.1)^{+}$ & $9.1(2.1,39.5)^{+}$ \\
\hline Fibrosarcoma & $0.5(0.1,2.0)$ & $1.0(0.1,16.0)$ \\
\hline GIST & $1.0(0.7,1.4)$ & $4.0(2.8,5.7)^{+}$ \\
\hline Leiomyosarcoma & $1.5(0.6,3.5)$ & $5.5(2.1,15.0)^{+}$ \\
\hline Liposarcoma & Not estimable & $2.5(0.9,7.6)$ \\
\hline $\mathrm{MFH}^{\mathrm{b}}$ & $1.4(0.6,3.3)$ & $19.7(3.7,106.0)^{+}$ \\
\hline$N S T^{c}$ & $2.1(0.8,5.4)$ & $4.4(1.1,17.5)^{+}$ \\
\hline Sarcoma NOS ${ }^{d}$ & $1.9(1.4,2.6)^{+}$ & $5.2(3.8,6.9)^{+}$ \\
\hline
\end{tabular}

All models adjusted for age at index/diagnosis date. Estimates represent the relative risk of VTE event in the 12 months before or after diagnosis/index date. STS patients 3,840; non-cancer patients $=3,480$. VTE Venous Thromboembolic Event (including deep vein thrombosis, pulmonary embolism, and other thromboembolic events). OTE category includes the following diagnoses: central retinal vein occlusion, venous tributary (branch) occlusion, nonpyogenic thrombosis of intracranial venous sinus, phlebitis/thrombophlebitis of superficial vessels of lower extremities, phlebitis/thrombophlebitis of superficial veins of upper extremities, phlebitis/thrombophlebitis of other sites, gout with other specified manifestations, Budd-Chiari syndrome, and venous embolism/ thrombosis of renal vein.

a Hazard ratios for STS subtypes other than those listed were not estimable due to small numbers.

${ }^{b}$ Maligant fibrous histiocytoma.

c Nerve sheath tumor.

d Sarcoma not otherwise specified.

+ Statistically significant. pulmonary disease, obesity, arterial thromboembolism, inherited prothrombotic mutations, prior history of VTE, performance status, advanced stage cancer, major surgery, hospitalization, chemotherapy, hormone therapy, anti-angiogenic agents, erythropoiesis-stimulating agents, transfusions, and central venous catheters $[7,12$, 18]. In our predictive models, many of these risk factors proved to be predictors of VTEs in the 12 months after STS diagnosis.

A few interesting differences are worth discussion. Atherosclerosis was a strong predictor for DVT, PE and OTE events in our data. This condition is not generally mentioned as a risk factor for VTE among cancer patients; however, cardiovascular literature has suggested a link between these two conditions [19-22]. We also observed that central venous catheterization, high-risk surgery, and surgery of primary were associated with a decreased risk of DVT after STS diagnosis. Decreased risk in this subgroup of patients is likely due to the close monitoring and prophylactic treatment for venous thromboses in surgical and catheterization situations.

Finally, our analysis compared the risk of VTE events in STS versus non-cancer patients both before and after STS diagnosis. Our study found that patients with angiosarcoma and sarcoma NOS were more likely to have experienced a VTE in the recent past (i.e. 12 month before STS diagnosis) than non-cancer individuals. These results support the theory that VTE could be a risk marker for an ensuing STS diagnosis or, perhaps, a misdiagnosis. Several authors of case studies suggested that STS may present as or be mistaken for a VTE, underlining the importance of investigating potential tumors when diagnosing VTE. In particular, STSs of the lower extremities have been misdiagnosed as DVTs [23-26] and pulmonary sarcomas/leiomyosarcomas have been misdiagnosed as pulmonary embolisms [27-40].

There are several strengths of note for this study. To our knowledge, this is the first study to examine VTEs among older STS patients. In this analysis we were able to focus on STS patients in particular, rather than the broader category of sarcoma which includes bone sarcomas. The STS patient cohort was large $(\mathrm{n}=3,840)$ allowing us to provide data by STS subtype. The wealth of the data in the SEER-Medicare database allowed us to quantify the occurrence of TE events before STS diagnosis and during various time periods after STS diagnosis, and to make comparisons between STS patients and agematched non-cancer individuals. Furthermore, we were able to adjust for and/or stratify by important covariates in our analysis. No previous studies performed multivariate analyses on STS patients nor did they investigate the timing of VTE events among STS patients. 
As in any study, limitations were present. Many effect estimates are imprecise, present with wide confidence intervals, and should be interpreted cautiously with the direction of the effect emphasized over the magnitude. The STS classification of MFH was changed in 2002 because the large majority of tumors formerly classified as $\mathrm{MFH}$ can be more meaningfully classified as other tumor types. However, due to the timeframe of SEERMedicare data collection, the old categorization had to be used for this study. The results based on this older cohort (i.e., 65 years or older) are generalizable only to those of the same age group. Also, information on some behavioral risk factors such as smoking, sedentary lifestyle, immobility, and CVD family history was unavailable. Finally, we had no access to information about potential predictive biomarkers such as elevated platelet or leukocyte counts, tissue factor, soluble p-Selectin, D-dimer, factor V Leiden, and prothrombin 20210A mutations [12, $41,42]$.

\section{Conclusion}

This is the first study to perform an in depth analysis of VTEs among older STS patients. Our results indicate that STS patients are at increased risk of VTEs after cancer diagnosis and that patients with a history of VTE are much more likely to have a subsequent VTE in the 12 months after their sarcoma diagnosis. VTEs are common and serious co-morbidities that should be closely monitored in older STS patients, particularly during the first 3 months after diagnosis and among those with a recent history of a VTE.

\section{Authors' contributions}

SS participated in study conception and design, data analysis, data interpretation and manuscript drafting. ACF participated in study design, data analysis, data interpretation and manuscript drafting. MK participated in study design, data analysis and manuscript drafting. RA participated in data analysis and data interpretation. LL participated in data analysis and data interpretation. All authors read and approved the final manuscript.

\section{Author details \\ ${ }^{1}$ Worldwide Epidemiology, Research and Development, GlaxoSmithKline, 150 Beach Road, \#26-00 Gateway West, Singapore 189720, Singapore. ${ }^{2}$ Frost Consulting, Epidemiologic Research and Grant Writing, Charlotte, NC, USA. ${ }^{3}$ Worldwide Epidemiology, Research and Development, GlaxoSmithKline, Research Triangle Park, NC, USA. ${ }^{4}$ Center for Observational Data Analytics, Amgen, Thousand Oaks, CA, USA.}

\section{Acknowledgements}

This study used the linked SEER-Medicare database. The interpretation and reporting of these data are the sole responsibility of the authors. The authors acknowledge the efforts of the Applied Research Program, NCl; the Office of Research, Development and Information, CMS; Information Management Services (IMS), Inc.; and the Surveillance, Epidemiology, and End Results (SEER) Program tumor registries in the creation of the SEER-Medicare database. We would like to thank Sue Hall, Jerzy Tyczynski, and Annette Beiderbeck for their contributions to the original objectives and variable definitions for this project. We are also grateful to Jeanenne Nelson for reviewing results throughout the analysis process.

\section{Compliance with ethical guidelines}

\section{Competing interests}

The authors declare that they have no competing interests.

Received: 11 May 2015 Accepted: 16 July 2015

Published online: 26 July 2015

\section{References}

1. Sorensen HT, Mellemkjaer L, Olsen JH, Baron JA (2000) Prognosis of cancers associated with venous thromboembolism. N Engl J Med 343:1846-1850

2. Chew HK, Wun T, Harvey D, Zhou H, White RH (2006) Incidence of venous thromboembolism and its effect on survival among patients with common cancers. Arch Intern Med 166:458-464

3. Khorana AA, Francis CW, Culakova E, Kuderer NM, Lyman GH (2007) Thromboembolism is a leading cause of death in cancer patients receiving outpatient chemotherapy. J Thromb Haemost 5:632-634

4. Agnelli G, Bolis G, Capussotti L, Scarpa RM, Tonelli F, Bonizzoni E et al (2006) A clinical outcome-based prospective study on venous thromboembolism after cancer surgery: the @RISTOS project. Ann Surg 243:89-95

5. Blom JW, Vanderschoot JP, Oostindier MJ, Osanto S, van der Meer FJ, Rosendaal FR (2006) Incidence of venous thrombosis in a large cohort of 66,329 cancer patients: results of a record linkage study. J Thromb Haemost 4:529-535

6. Khorana AA, Francis CW, Culakova E, Fisher RI, Kuderer NM, Lyman GH (2006) Thromboembolism in hospitalized neutropenic cancer patients. J Clin Oncol 24:484-490

7. Khorana AA, Francis CW, Culakova E, Kuderer NM, Lyman GH (2007) Frequency, risk factors, and trends for venous thromboembolism among hospitalized cancer patients. Cancer 110:2339-2346

8. Khorana AA, Kuderer NM, Culakova E, Lyman GH, Francis CW (2008) Development and validation of a predictive model for chemotherapyassociated thrombosis. Blood 111:4902-4907

9. Levitan N, Dowlati A, Remick SC, Tahsildar HI, Sivinski LD, Beyth R et al (1999) Rates of initial and recurrent thromboembolic disease among patients with malignancy versus those without malignancy. Risk analysis using Medicare claims data. Medicine (Baltimore) 78:285-291

10. Sallah S, Wan JY, Nguyen NP (2002) Venous thrombosis in patients with solid tumors: determination of frequency and characteristics. Thromb Haemost 87:575-579

11. Stein PD, Beemath A, Meyers FA, Skaf E, Sanchez J, Olson RE (2006) Incidence of venous thromboembolism in patients hospitalized with cancer. Am J Med 119:60-68

12. Khorana AA, Connolly GC (2009) Assessing risk of venous thromboembolism in the cancer patient. J Clin Oncol 27(29):4839-4847

13. Wun T, White RH (2009) Venous thromboembolism (VTE) in patients with cancer: epidemiology and risk factors. Cancer Invest 27(Suppl 1):63-74

14. Damron TA, Wardak Z, Glodny B, Grant W (2010) Risk of venous thromboembolism in bone and soft-tissue sarcoma patients undergoing surgical intervention: a report from prior to the initiation of SCIP measures. J Surg Oncol 103(7):643-647

15. Mitchell SY, Lingard EA, Kesteven P, McCaskie AW, Gerrand CH (2007) Venous thromboembolism in patients with primary bone or soft-tissue sarcomas. J Bone Joint Surg Am 89:2433-2439

16. Lee AY, Levine MN (2003) Venous thromboembolism and cancer: risks and outcomes. Circulation 107:117-121

17. Anderson FA Jr, Spencer FA (2003) Risk factors for venous thromboembolism. Circulation 107:19-16

18. Sousou T, Khorana A (2009) Identifying cancer patients at risk for venous thromboembolism. Hamostaseologie 29:121-124

19. Agnelli G, Becattini C (2006) Venous thromboembolism and atherosclerosis: common denominators or different diseases? J Thromb Haemost 4:1886-1890

20. Prandoni P, Bilora F, Marchiori A, Bernardi E, Petrobelli F, Lensing AW et al (2003) An association between atherosclerosis and venous thrombosis. N Engl J Med 348:1435-1441 
21. Prandoni $P$ (2007) Venous thromboembolism and atherosclerosis: is there a link? J Thromb Haemost 5(Suppl 1):270-275

22. van der Hagen PB, Folsom AR, Jenny NS, Heckbert SR, O'Meara ES, Reich LM et al (2006) Subclinical atherosclerosis and the risk of future venous thrombosis in the Cardiovascular Health Study. J Thromb Haemost 4:1903-1908

23. Benns M, Dalsing M, Sawchuck A, Wurtz LD (2006) Soft tissue sarcomas may present with deep vein thrombosis. J Vasc Surg 43:788-793

24. Emori M, Naka N, Hamada K, Tomita Y, Takami H, Araki N (2010) Soft-tissue sarcomas in the inguinal region may present as deep vein thrombosis. Ann Vasc Surg 24:951

25. Arumilli BR, Babu VL, Paul AS (2008) Painful swollen leg-think beyond deep vein thrombosis or Baker's cyst. World J Surg Oncol 6:6

26. Singh NK, Kolluri R (2009) Liposarcoma of thigh presenting as deep venous thrombosis. Phlebology 24:139-141

27. Kruger I, Borowski A, Horst M, de Vivie ER, Theissen P, Gross-Fengels W (1990) Symptoms, diagnosis, and therapy of primary sarcomas of the pulmonary artery. Thorac Cardiovasc Surg 38:91-95

28. Chang SK, Wang TL, Teh M (1996) Extraskeletal Ewing's sarcoma presenting with pulmonary embolism. Australas Radiol 40:175-178

29. Cox JE, Chiles C, Aquino SL, Savage P, Oaks T (1997) Pulmonary artery sarcomas: a review of clinical and radiologic features. J Comput Assist Tomogr 21:750-755

30. Richards AM, Tiernan EP, Cole RP, Hobby JE (1997) Are soft-tissue sarcomas of the thigh particularly prone to thromboembolic phenomena? Plast Reconstr Surg 100:1074-1075

31. Kanjanauthai S, Kanluen T, Ray C (2008) Pulmonary artery sarcoma masquerading as saddle pulmonary embolism. Heart Lung Circ 17:417-419

32. Sandhu A, Yates TJ, Kuriakose P (2008) Pulmonary artery sarcoma mimicking a pulmonary embolism. Indian J Cancer 45:27-29
33. Minakata K, Konishi Y, Matsumoto M, Aota M, Nonaka M, Yamada N (2000) Primary leiomyosarcoma of the pulmonary artery mimicking massive pulmonary thromboembolism. Jpn Circ J 64:783-784

34. Hoffmeier A, Semik M, Fallenberg EM, Scheld HH (2001) Leiomyosarcoma of the pulmonary artery - a diagnostic chameleon. Eur J Cardiothorac Surg 20:1049-1051

35. Hollenbeck ST, Grobmyer SR, Kent KC, Brennan MF (2003) Surgical treatment and outcomes of patients with primary inferior vena cava leiomyosarcoma. J Am Coll Surg 197:575-579

36. Hilliard NJ, Heslin MJ, Castro CY (2005) Leiomyosarcoma of the inferior vena cava: three case reports and review of the literature. Ann Diagn Pathol 9:259-266

37. Dew J, Hansen K, Hammon J, McCoy T, Levine EA, Shen P (2005) Leiomyosarcoma of the inferior vena cava: surgical management and clinical results. Am Surg 71:497-501

38. Shindo S, Katsu M, Kaga S, Inoue H, Ogata K, Matsumoto M (2009) Leiomyosarcoma of a femoral vein misdiagnosed as deep vein thrombosis. J Vasc Interv Radiol 20:689-691

39. Parissis H, Akbar MT, Young V (2010) Primary leiomyosarcoma of the right atrium: a case report and literature update. J Cardiothorac Surg 5:80

40. Neragi-Miandoab S, Kim J, Vlahakes GJ (2007) Malignant tumours of the heart: a review of tumour type, diagnosis and therapy. Clin Oncol (R Coll Radiol) 19:748-756

41. Blom JW, Doggen CJ, Osanto S, Rosendaal FR (2005) Malignancies, prothrombotic mutations, and the risk of venous thrombosis. JAMA 293:715-722

42. Kessler CM (2009) The link between cancer and venous thromboembolism: a review. Am J Clin Oncol 32:S3-S7

\section{Submit your next manuscript to BioMed Central and take full advantage of:}

- Convenient online submission

- Thorough peer review

- No space constraints or color figure charges

- Immediate publication on acceptance

- Inclusion in PubMed, CAS, Scopus and Google Scholar

- Research which is freely available for redistribution

Submit your manuscript at 